\title{
Research on the Construction of Multiple Development Pattern of Green Economy in China
}

\section{LIU Yingyuan}

\author{
School of Economics and Management, Hubei University of Technology, Wuhan, 430068, China \\ email: 2500207860@qq.com
}

Key words: Green Economy, Multiple Development Pattern, Construction

\begin{abstract}
Nowadays, promoting the green economy is essential to fight against the current financial crisis and global climate change because of the increasingly role in employment, economy development, environmental protection and sustainable development. Meanwhile, it can adjust the global economic structure and reduce green barriers in international trade. Based on some features in our current development, this paper discusses the necessity of developing green economy in our country by analyzing the green economy and encourages the multiple development pattern of green economy. This paper holds that we should promote green economy by strengthening the macro-control of the government, the implementation of the green brand strategy by the enterprises and raising the consumers' awareness of green consumption. The research can further enrich the green economy theory and provide a scientific basis for the development of green economy in China.
\end{abstract}

\section{Introduction}

With the rise of the green movement in the western developed countries in the 1960s, the concept of green economy has been popularized in the field of economics. From "green production" to "green consumption", "green circulation” to "green distribution”, "green technology" to "green system”, "green development” to "green civilization”, tremendous economics concepts are added a "green" prefix and the green economy has emerged as a hot topic of economic research and discussion. [1] Firstly appearing in the "Green Economy Blue Book", the green economy is a market-oriented and balanced economy to achieve harmony between economy and environment, which is based on traditional industrial ecology and sets the resource-saving, environment-friendly green economy as the basic industrial chain.

The green economy is gradually emerging as the focus of the new round of international competition and the main engine of the future economy. Promoting the green economy is essential to fight against the current financial crisis and global climate change. It can stimulate employment, boost the economy, enhance the environmental protection and sustainable development, effectively adjust the global economic structure and reduce green barriers in international trade. [2] Though some achievements have been made in developing the green economy, China still faces some problems, such as insufficient investment, weak public awareness of green consumption and the industry's hindrance to green barriers in developed countries.

\section{Necessity to develop green economy}

\section{Measure to fight against the current financial crisis and global climate change}

Since the outbreak of the financial crisis, the stimulus economy plans introduced by every country have enabled that numerous funds flowed into the traditional industry, which may lead to ecological deterioration and pollution. Even if the economy is recovering, it will pay a high price. The challenges brought by financial crisis and climate change mean that we should restructure the 
entire economy and the industry structure. Without bubble, the green economy can effectively alleviate the impact of the financial crisis on the real economy and ease the environmental deterioration and climate warming. A United Nations study shows that the economic returns and benefits of employment brought by investing in natural protection or ecological infrastructure are much higher than those generated by traditional industries such as automobile manufacturing and steel. [3]Therefore, for high-energy-consuming enterprises, promoting new energy and reducing energy consumption is the best choice, which can help to overcome crisis and promote sustainable development.

\section{Promoting the green economy can boost employment and economy}

The green economy boasts a huge market potential. The promotion of the green economy with large investment in new technologies, equipment, buildings and infrastructure will stimulate new employment opportunities, protect the vulnerable groups and ease employment pressures. With the rapid expansion of current wind energy and solar utilization, it is estimated that under the sound investment expectation the global wind energy field will employ 2.1 million people by 2030 and the solar photo-electricity industry will hire over 6.3 million people. [4] In addition, the energy consulting services will gradually gain momentum. In the construction industry, transforming the commercial and residential building and enhancing its energy efficiency will create significant job opportunities for builders, architects and energy auditors. In agriculture, organic agriculture is more labor intensive than industrial agriculture and will likely become a source of additional green jobs in the future. [5] However, the transition to the green economy will involve major changes in employment patterns and skill needs and lead to major implications to resource mining and energy intensive industries. This requires more assistance to diversify them as a way to create more jobs and ensure its staff gains new skills. This will be a long transition.

\section{Be conductive to environmental protection and sustainable development}

Human beings is facing a huge revolution of green economy, which puts the people's interests higher on the agenda, emphasizes economy development and improvement of people's living standard and ensures the harmonious coexistence between human and nature, human and environment. The traditional investment focuses on obtaining and short-term return. The short-term "two high and one resource" (high energy consumption, high pollution and resource) program is a damaging economy featuring fast returns, ecological balance destruction, energy and resource consumption and damage to people's health; the green economy is a balanced economy as a way to protect the environment for human survival, protect resources and energy and protect people's health. From the perspective of development, the investment to green economy not only can meet various challenges but also create lots of opportunities. From the practice of the developed countries, the green economy can not only maximize the economic benefit but also guarantee the virtuous cycle of ecosystem. The green economy can provide safe guarantee for people's food and clothing and ecological security for environment to make people live in harmony with nature. Therefore, it is imperative to development green economy from the perspective of long-term sustainable development of our country.

\section{Adjusting the global economic structure and reducing the green barriers in international trade}

“Green competition” will have a profound impact on the global economic landscape and significantly stimulate the green industrial revolutions carried out by every nation. Therefore, a pattern featuring global green competition will take shape. As the world's largest economy, oil importer and consumer, the United States' new energy strategy will exert a significant impact on global green industrial revolution. With its breakthrough in new energy technology, it will rely less on foreign oil and its demands for import and international oil market will be reduced. Its economy will be mainly driven by the rapid development of new energy industry. Many industries involved will develop quickly, and the economy will grow in a different way and influence the economies in other regions, thus forming the new focus of its real economy and spreading its technology to other 
countries. Green economy develops by constantly arming and reforming the enterprises with new technology, which will improve the industry quality, enhance and upgrade the structure. To reduce green barriers, we should choose a pattern driven by sustainable development, improve the economic strength and make enterprises and products more competitive. The appearance of green barriers is inevitable, and developing green economy is fundamental to reduce these barriers.

\section{Construction of multiple development pattern of green economy}

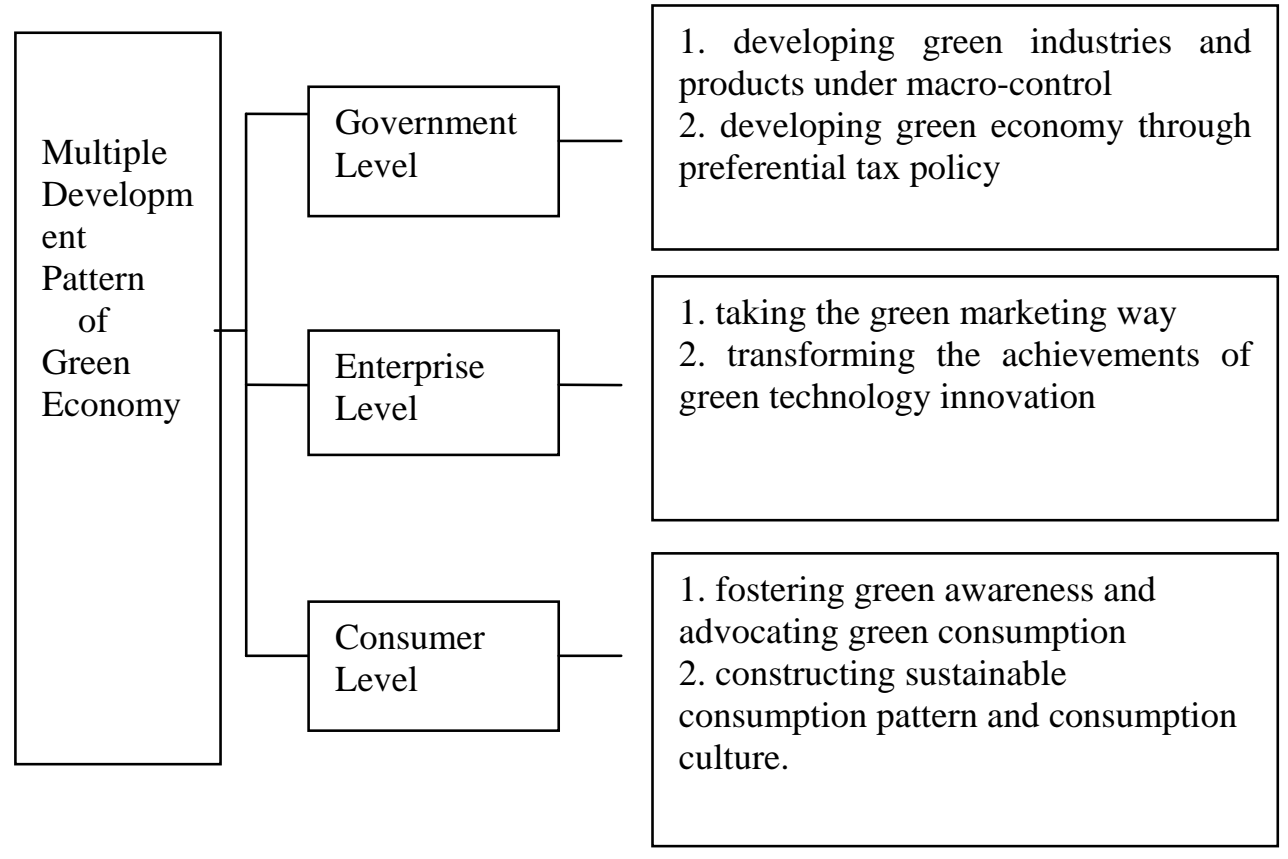

Figure 1 Multiple Development Pattern of Green Economy

\section{Government Level}

\section{Developing green industries and products under macro-control}

The government should carry out macro-control, reconstruct the industry and product structure based on an environmental plan, and develop green industries and products to make the environment of regional economy more sustainable. It should learn from America about energy use and give up the "saving after using" pattern to build a conservation-minded society. Green economy tracking and assessing system should be established to know more about departments and predict their development. The government should make and enforce laws about resource management and environmental protection, and make and implement economic policy. Enterprises which contribute to green economy should be given preferences, while those which violates should be limited, punished or banned.

\section{Developing green economy through preferential tax policy}

The government should properly reduce the tax of those green products sellers to cut down their costs by using tax policy. Through fiscal policy subsidy, it should make the preferential policy of green economy available to enterprises. And it should first give soft loans to those enterprises involved in green projects, lower the demands for loan, set up special investment fund for green industry and green bank, and develop diversified financing ways such as green bonds and energy-saving funds by using monetary policy. Industry policy should be applied to encourage and support green economy, make the investment in green projects more efficient, develop green industries with local colors and give funds and policy support to the emerging environmentally friendly industry so as to fundamentally change the conventional business pattern of ignoring the rare resources and the benefits of human consumption. 


\section{Enterprises Level}

\section{Taking the green marketing way}

Enterprises should take the green marketing way based on sustainable development. Developing, designing, producing, manufacturing, packaging and shipping should be guided by philosophy like resources conservation and environmental protection. Becoming more capable in developing and innovating green technology after knowing more information about green market the green demands of consumers, optimizing and upgrading the industrial structure vigorously, developing high and new technology, reforming traditional industry and developing pattern catering industry more quickly, it should promote the industries such as real estate, car and textile in a green way, fully recycle and decompose the wastes and recycle the package and its rubbish. It should set up special governance institutions to supervise and manage and strengthen the green cooperation between enterprises.

\subsubsection{Transforming the achievements of green technology innovation}

Starting from the industrialized operations, enterprises should learn and exchange views on foreign technology resources and achievements. In addition to technological innovation, it should innovate the relevant management patterns and regulations, make sure the achievements of green technology innovation are well transformed and make a proper price to inspire the consumption of green products. Measures like merger and acquisition should be adopted to expand the enterprise, make it stronger in green competition and promote its sustainable development through external resources. Using the green brand strategy to get recognition like green symbol and green products, thus setting up good image and reputation for green enterprises.

\section{Consumer Level}

\section{Fostering green awareness and advocating green consumption}

Consumers should develop new ideas of consumption, foster green awareness and advocate green consumption. The related departments should be responsible in spreading the green education to the whole nation, be stricter with the green authentication and supervision and crack down the illegal manufacturing and sales of green products to create a good environment for green consumption. To carry out this consumption pattern, consumers should be fully aware of what is green consumption. When buying something, consumers should choose green products of no pollution or more nutrition, dispose wastes more carefully and not pollute the environment.

\section{Constructing sustainable consumption pattern and consumption culture}

In 1944, the United Nations Environment Programme published the Policy Factors in Sustainable Consumption in Nairobi, the capital of Kenya. The report defines the sustainable consumption as "meeting the basic demands of human by providing service and related products, improving living standard, using natural resources and toxic materials as few as possible and making the least wastes and pollution in the life cycle of service and products so as not to damage the demands of next generation. "The consumption pattern and culture basically include replacing the value of materialism with that of knowledge and wisdom, excessive consumption with moderate consumption and luxury and waste with a simple life.

\section{Conclusion}

Green economy is a new driving force for a sustained and healthy world economy and is also a new commanding height of economy for every nation to fight for in the next competition. China will continue to develop green economy with Chinese characteristics to cope with many crises, change the old pattern of economic growth, and develop new energy and environmentally friendly industries more quickly. Look forward to the world and future when focusing on the basic problems like high energy and high pollution. Government, enterprises and consumers should work together to build green economy in all fields and procedures of economic development. 


\section{References}

[1] World Development Indicators. The World Bank Group. . 2012

[2] Advancing the Economics of Ecosystems and Biodiversity in Canada: A Survey of Economic Instruments for the Conservation and Protection of Biodiversity, University of Ottawa[N/OL]. Kenny A, Elgie S, Sawyer D. Sustainable Prosperity, Background Paper . 2011

[3]Development Mechanism and Policy Innovation of China's Green Economy. CCICED. Task Force Research Report . 2011

[4]Economics for the Environment Consultancy Ltd. Worley Parsons Canada Ltd. Water Valuation Guidance Document . 2010

[5]Global Green New Deal: An Update for the G20Pittsburgh Summit. UNEP. . 2009 